\title{
MÉTODOS DE MEDIÇÃO DA ÁGUA NO SOLO : UMA BREVE DISCUSSÃO
}

\author{
Mário Diniz de Araújo Neto(*)
}

\begin{abstract}
In this paper measuring methods of ground water in soils are discussed, as a help for geoscientists who are working with experimental studies in hydrology. There are presented methods which use lysometers, tensiometers, and neutron probe with its respective installation systems.

Finally, the paper tries to show the feasibility and utility of a field experiment for professional training of geoscience students.
\end{abstract}

\section{INTRODUÇÃO}

Pesquisas voltadas para a medição dos processos hidrológicos em bacias de drenagem, embora de grande utilidade para o gerenciamento dos recursos hídricos, ainda são escassas no Brasil. A maioria dos estudos são provenientes dos países desenvolvidos, notadamente Estados Unidos e Inglaterra. As primeiras pesquisas em bacias de drenagem começaram com a criação do Serviço de Conservação do Solo dos Estados Unidos, no final da década de 30. Ressalta-se ainda que foi nos anos 30 que surgiram os resultados dos trabalhos de Horton (1933) que marcaram profundamente o desenvolvimento da pesquisa hidrológica.

Os resultados dos estudos desenvolvidos nos Estados Unidos em pequenas áreas (plots) nas bacias de drenagem, forneceram valiosas informações sobre os efeitos do uso da terra e características físicas do solo, nas quantidades e taxas de escoamento superficial. O desenvolvimento da equação universal de perda de solo é um exemplo importante do que foi conseguido através dos estudos em tais áreas (Amermann \& McGuiness 1967).

O trabalho de Horton (1933), resulta em um modelo para a previsão do "Runoff" (aqui definido como toda água que escoa em uma bacia de drenagem), baseado na capacidade de infiltração do solo, a qual declina até atingir uma taxa constante após 1 hora e meia a 2 horas do início da chuva. Durante a chuva, se a capacidade de infiltração do solo for excedida a água acumula-se preenchendo as pequenas depressões do terreno. Se, subsequentemente a capacidade de armazenamento das depressões for exaurida, a água flui declive abaixo, como um lençol irregular chamado escoamento superficial, i.e, água que escoa diretamente sobre a superfície do terreno, em direção aos rios.

Até 1960, as principais aplicações da hidrologia eram para construção de reservatórios e previsão das cheias dos rios. Os fundamentos da ciência hidrológica repousavam na eficiência de alguns conceitos, especialmente na teoria da infiltração do escoamento superficial (proposta por Horton 1933) e no modelo da hidrógrafia unitária (Sherman 1932), para a previsão da descarga dos rios após eventos de precipitação pluviométrica. Previsões das vazões dos rios baseadas nestas idéias eram adequadas para grandes bacias de drenagem, porém pouco eficazes para pequenas áreas de cabeceira de drenagem (Kirkby 1980). Ainda na década de 1960, o crescente interesse pelos processos hídricos mostrou o quão pouco se sabia acerca das origens das águas superficiais de alta qualidade provenientes das nascentes dos rios. As explicações clássicas a despeito da origem das águas dos rios quer durante períodos secos ou chuvosos, foram refutadas por resultados obtidos no Laboratório Hidrológico de Coweeta na Carolina do Norte. Demonstrou-se que em declives íngremes cobertos por florestas com rios encaixados e solos moderadamente profundos, o escoamento superficial produzido pelas chuvas era desprezível. Acrescente-se ainda que alguns poços de observação, naquelas áreas, não demonstraram aquíferos saturados, exceto ao longo das margens dos rios ou em linhas de drenagem onde havia o afloramento das águas do lençol freático (Hewlett \& Hibbert 1963). As conclusões deste e outros estudos subsequentes, evidenciaram que em climas úmidos o fluxo de água subterrânea (baseflow) que alimenta os cursos de água em período de estiagem é proveniente da água armazenada no manto de solo. Em períodos chuvosos a descaga dos rios (stormflow) é suprida por águas subsuperficiais (interflow) que fluem através dos diferentes horizontes do solo. As áreas de origem dos fluxos acima mencionados estão sujeitas a contração e expansão, dependendo da quantidade e duração da chuva. (Figura 1).

Os trabalhos de Hewlett (1961) e Hewlett \& Hibbert (1967), resultaram em modelos (variable source area models) que tratam do movimento das águas subsuperficiais. Estes modelos são hoje aceitos para representar as trajetórias, tempo de permanência e origens da água que flui nas cabeceiras de drenagem.

* Departamento de Geografia - UnB 


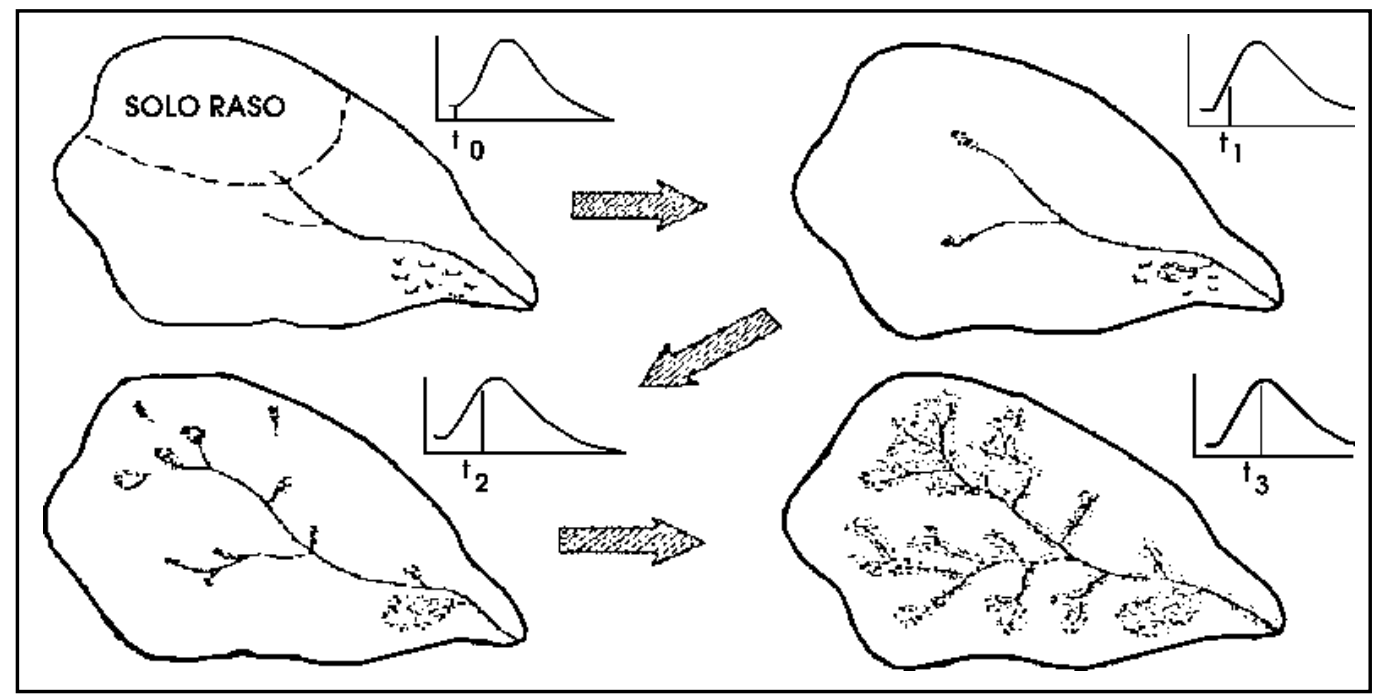

Figura 1: Esquema mostrando o aumento das áreas de contribuição à descarga dos rios, em uma bacia

hidrográfica, durante um evento pluviométrico, de acordo com Hewlett (1982). As setas nos tempos $t_{0^{\prime}} t_{1}, t_{2} e t_{3}$ mostram o aumento da descarga, a medida que ocorre a expansão da área de contribuição variável

Figure 1: Schematic diagram of source area and stream expansion (after Hewlett 1982). The small arrows at times $t_{0}, t_{1}, t_{2}$, and $t_{3}$ show the increase of streamflow as the variable source area expands into marshes, shallow soils and ephemeral channels.

O modelo do escoamento proposto por Horton (1993) (Horton Runoff Model) têm sua aplicação restrita à áreas impermeáveis ou localizadas que sofreram perturbações antrópicas.

Estudando os componentes do fluxo de água em vertentes, Kirkby (1969), confirmou que o fluxo subsuperficial é o fluxo dominante em vertentes das áreas em clima temperado-úmido. Demonstrou também que em regiões semi-áridas o escoamento superficial (overland flow, proposto por Horton) é o processo dominante quando a intensidade da chuva excede a capacidade de infiltração do solo. Concluiu ainda que em condições adequadas ambos fluxos superficiais e subsuperficiais podem ocorrer em qualquer ponto da bacia de drenagem, embora variam em termos de freqüência de um local para outro. Partindo deste estudo, Kirkby (1969) propôs um modelo simples para explicar a descarga do fluxo subsuperficial ao longo de uma vertente (Figura 2). Entretanto, embora modelos como os de Hewlett e de Horton, encontrem larga aplicação em uma variedade de locais, há poucos experimentos elaborados para verificar a estrutura de tais modelos e sua adequação para outras áreas. Por exemplo, nas regiões tropicais úmidas, há indicações que vários tipos de fluxos (escoamento superficial, subsuperficial e escoamento superficial em solo saturado por afloramento do lençol freático), ocorrem em uma mesma bacia de drenagem (Dubreuil 1985). Além disso, resultados obtidos em experimentos efetuados em áreas temperadas-úmidas, levantam dúvidas a respeito da validade do modelo de Hewlett para explicar a disposição das águas em bacias de drenagem de áreas montanhosas (Baloutsos 1985). Aliado a esta dificuldade há o problema da escassez de experimentos com rigor estatístico suficiente para a validação dos modelos, e a questão da representatividade dos dados, conforme observado por

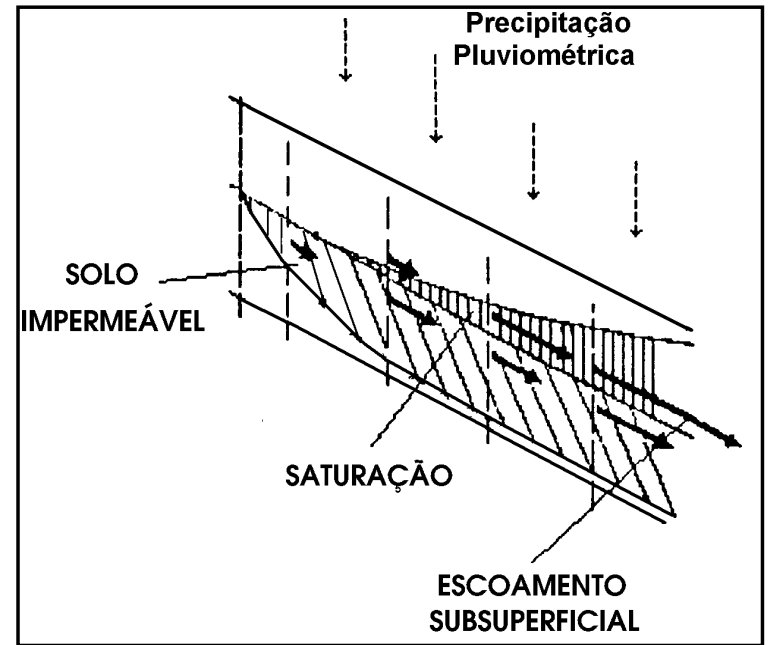

Figura 2: Descarga do fluxo de água subsuperficial proposto por Whipkey \& Kirkby (1980).

Figure 2: Saturated soil layers and subsurface flow above and below the contact impeding layer (after Whipkey \& Kirkby 1980).

Burt \& Walling (1984). As dificuldades aparecem devido a falta de amostras suficientemente grandes para a previsão acurada das características numéricas de uma variável. Muitas vezes apenas um evento pluviométrico ou uma amostra de solo ou poucas medidas de laboratórios são utilizadas para apoiar as principais conclusões dos trabalhos. Em observação semelhante Freeze (1978) afirmou que a escassez de dados representativos impõe sérias limitações na elaboração de modelos matemáticos para explicar processos hidrológicos nas vertentes.

Levando em conta os problemas acima expostos, planejou-se o trabalho aqui apresentado, com o objetivo de fornecer informações detalhadas acerca dos processos de escoamento da água em uma vertente, 
incluindo considerações sobre a acurácia dos resultados. Procurou-se, assim, contribuir para o aumento de informações sobre processos hidrológicos que somadas aos já existentes permitissem a elaboração de modelos mais exatos.

Obviamente, dadas as características climáticas da área de estudos, não há possibilidade de extrapolação dos resultados e conclusões, obtidas nesse trabalho, para pequenas bacias de drenagem no Brasil. Entretanto, julgou-se oportuno a apresentação e discussão dos métodos utilizados na pesquisa, principalmente o uso da sonda de neutrons, como forma de contribuir com outros pesquisadores que estejam trabalhando em projetos semelhantes. Além disso trata-se de um experimento de baixo custo acessível à maioria dos pesquisadores universitários e que pode ser acompanhado por alunos de graduação. A sugestão para a repetição desse trabalho em outras áreas prende-se a necessidade do treinamento dos alunos na observação dos fenômenos naturais e suas variações. Nesse sentido, é importante familiarizar os estudantes com a aplicação do método dedutivo para fundamentação de suas hipóteses sobre o comportamento das variáveis ambientais. No caso específico desse experimento procurou-se elucidar as condições que governam a distribuição da água da chuva no solo, no sentido de testar os modelos conhecidos, de Horton e de Hewlett, que exploram a distribuição da água no solo.

\section{METODOLOGIA}

O experimento de campo constituiu-se de medições repetidas, ao longo de dezoito meses, da precipitação pluviométrica, escoamento superficial, potencial da água e volume da água no solo utilizando-se pluviômetros, lisímetros, tensiômetros e sonda de neutrons. O uso de réplicas foi uma característica essencial do desenho do experimento, dado o objetivo de aumentar as informações disponíveis acerca dos fluxos de água, levando em conta as variações e a melhoria na precisão dos resultados.

\section{Objetivo dos métodos experimentais}

O objetivo do experimento foi descrever a variabilidade dos fluxos de água sobre um segmento de vertente coberto por gramíneas em uma pequena bacia de drenagem.

Isto envolveu a comparação entre quatro lisímetros e considerações sobre os erros das medições. Tentouse separar os fluxos de água em componentes laterais, oriundos dos horizontes do solo, e verticais, que ocorriam no interior do perfil. Para tal estudo foi necessário a obtenção dos seguintes dados:

- quantidade de chuva;

- evapotranspiração;

- escoamento superficial;

- fluxos laterais nos limites entre os horizontes;

- teor de água no solo e sua variação em diferentes profundidades;

- potencial da água em diferentes profundidades.

\section{Preparação da área de estudos}

O experimento foi montado em uma área cercada de $224 \mathrm{~m}^{2}$, em uma seção retilínea de uma encosta voltada para o sul, com ângulo de inclinação de $13^{\circ}$, em uma fazenda experimental da Universidade de Edimburgo/Escócia. A disposição dos equipamentos tais como pluviômetro, pluvógrafo, lisímetros, baterias de tensiômetros e rede de tubos de acesso para a sonda de neutron é mostrada na Figura 3 e detalhes da construção de um dos lisímetros são mostrados na Figura 4.

Esta parte, em primeiro lugar, relata a construção dos lisímetros e a instalação dos demais equipamentos, discutindo os problemas encontrados e as soluções adotadas. Segue-se uma discussão sobre a rotina de medições semanais e dificuldades encontradas na operação dos equipamentos.

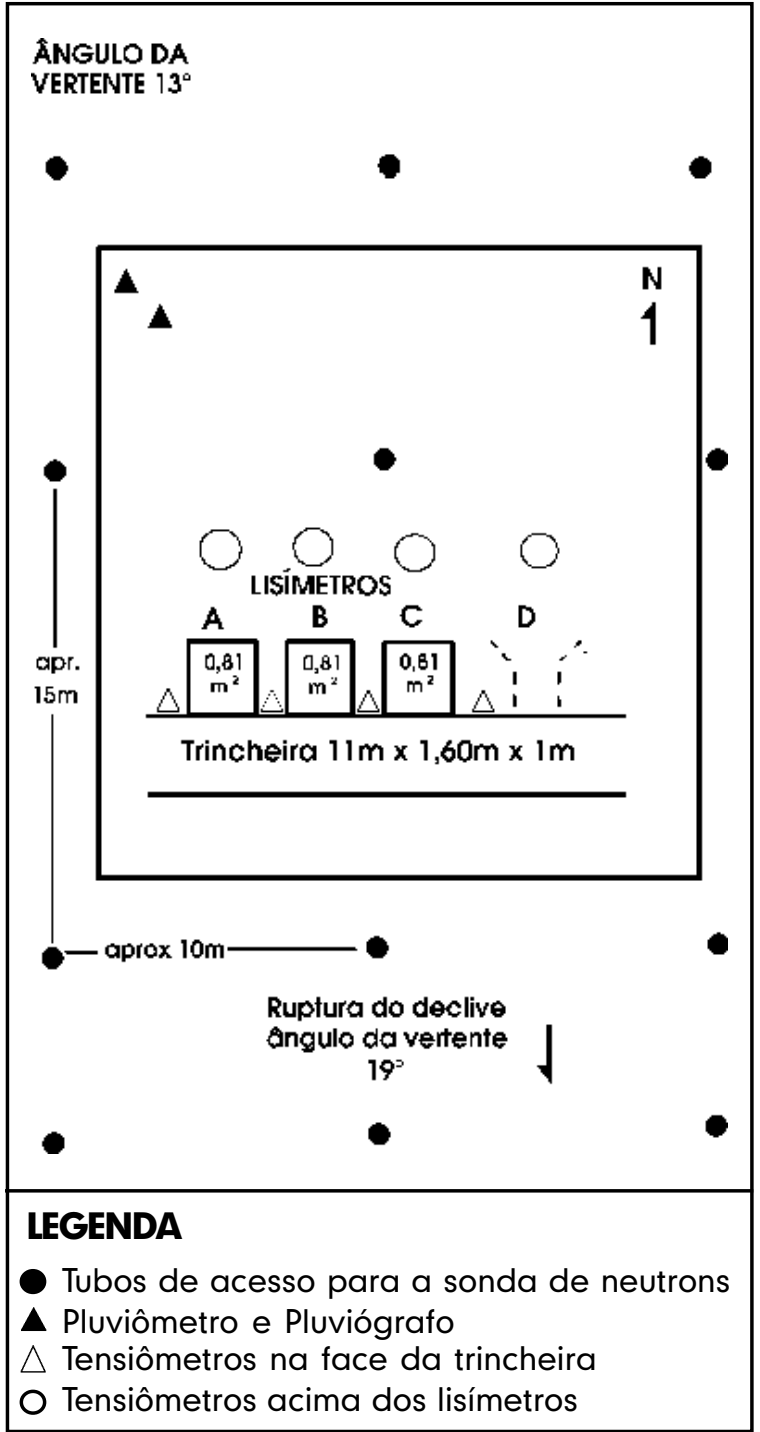

Figura 3: Diagrama esquemático da área de estudo mostrando a distribuição dos lisímetros e demais equipamentos.

Figure 3: Schematic diagram of the study area showing the plots ( $A, B, C$ and $D)$, tensiometers, raingauges, and neutron probe acces tubes. 


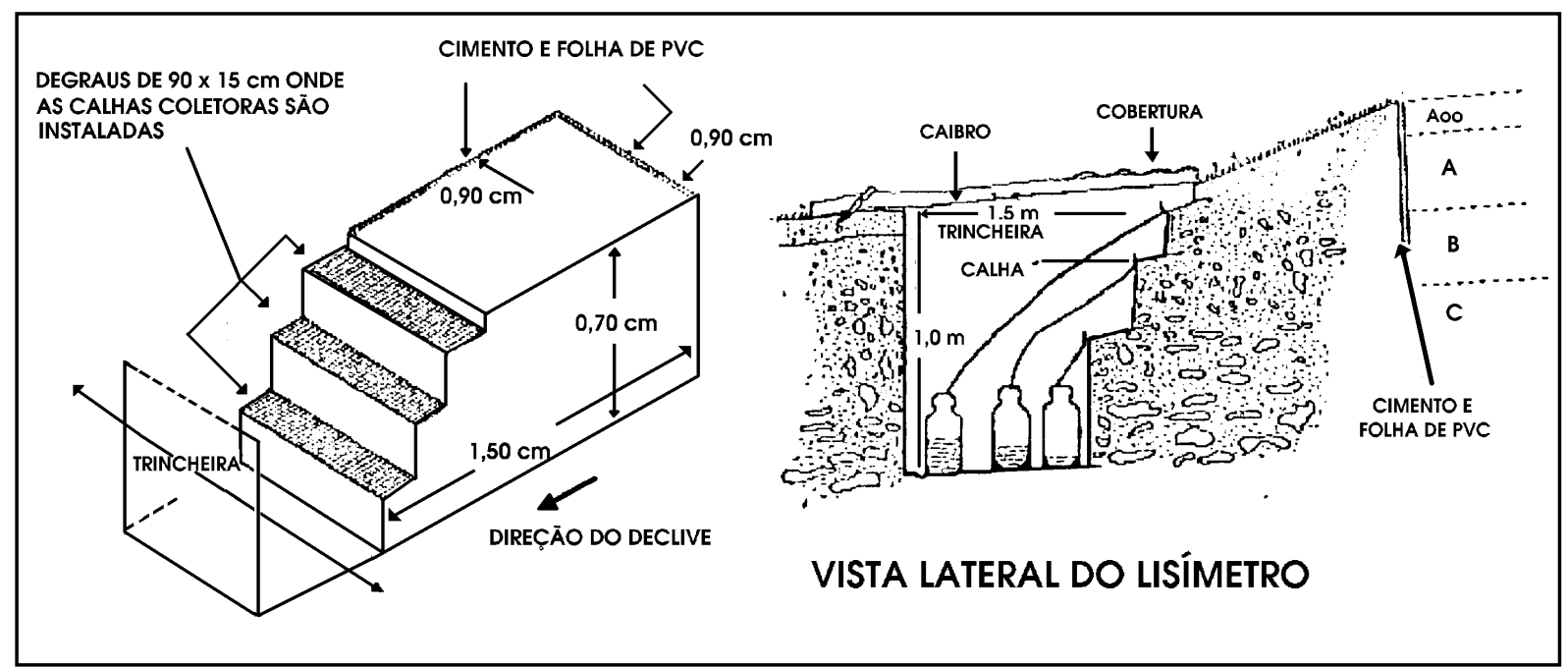

Figura 4: Esquema de um lisímetro escavado no solo, onde são vistos os "degraus" correspondentes aos horizontes do solo e onde ficam as calhas para coleta do fluxo lateral e os vasilhames para armazenamento da água.

Figure 4: Schematic diagram of one plot, showing the steps where PVC gutters were placed.

\section{Construção dos lisímetros e instalação dos equipamentos}

De acordo com Atkinson (1980), os métodos para medição da umidade em vertentes caem em três categorias:

1) métodos para a intercepção dos fluxos de água;

2) métodos envolvendo a adição de corantes para marcar a trajetória dos fluxos;

3) métodos indiretos, tais como o uso da sonda de neutrons e tensiômetros.

Neste experimento foram utilizados os métodos $1 \mathrm{e}$ 3. O primeiro serviu para captação dos fluxos d'água superficiais e subsuperficiais, que foram canalizados para vasilhames coletores. O objetivo foi medir o volume d'água drenando lateralmente com o fluxo de saturação, descobrir sob quais condições ocorriam tais fluxos e testar a confiabilidade do método. Os métodos indiretos empregados foram a sonda de neutrons para a determinação do teor d'água e tensiômetros para medir o potencial da água no solo.

A técnica de campo utilizada para coletar os fluxos d'água dos horizontes do solo assemelha-se àquela já descrita por Whipkey (1965), Dunne \& Black (1970), Weyman (1973) e Knapp (1973).

Primeiramente escavou-se uma trincheira medindo $11 \mathrm{~m}$ de comprimento por $1,60 \mathrm{~m}$ de largura e $1 \mathrm{~m}$ de profundidade com uma retroescavadeira-mecânica. $\mathrm{Na}$ face exposta do perfil foram construídos três lisímetros adjacentes de $1,5 \mathrm{~m}$ de comprimento por $0,9 \mathrm{~m}$ de largura e $0,7 \mathrm{~m}$ de profundidade. Os vazios, criados pela separação dos lisímetros do solo circundante, foram preenchidos com cimento, e usando folhas de PVC com $5 \mathrm{~mm}$ de espessura para evitar que o cimento escorresse e fosse garantida uma camada com uma espessura média de $5 \mathrm{~cm}$. A colocação da camada de cimento, nos três lados dos lisímetros, com tal espessura preveniu a ocorrência de vazamento d'água para o solo e vice-versa. Apoiando a folha de PVC, utilizou-se o material de solo previamente removido. Este procedimento assegurou que cada um dos lisímetros fosse construído como um monólito isolado, exceto na base, preservando-se assim inalterada a estrutura do solo.

Os três lisímetros foram construídos com 1,5m de separação (Figura 3). Na face livre de cada um foram entalhados 3 degraus para apoiar calhas de PVC medindo $92 \mathrm{~cm}$ de comprimento por $21 \mathrm{~cm}$ de largura. As calhas foram inseridas nos limites dos horizontes pedogenéticos para coletas d'água que minava do solo.

Esperava-se que os fluxos d'água aparecessem logo acima de uma camada de solo impeditiva da drenagem. Além disso acreditava-se que os fluxos na face livre dos lisímetros fossem reduzidos, devido a quebra da continuidade hidráulica durante a escavação da trincheira e que por isso haveria uma acumulação de água declive acima, a partir da face exposta do perfil do solo, conforme observado por Atkinson (1980).

Para tentar resolver o problema da quebra da continuidade hidráulica, preencheu-se as calhas com material fino do solo, afim de garantir um bom contacto hidráulico entre as calhas e o solo. Finalmente para garantir a separação dos fluxos de água de cada um dos horizontes, colocou-se uma folha de plástico nos limites dos horizontes conforme ilustra a Figura 5.

As calhas dos lisímetros foram protegidas da chuva com telhas de zinco, assegurando-se que a água coletada nos vasilhames fosse exclusivamente do solo.

A área de drenagem dos lisímetros, ao final da colocação das calhas, era de $0,81 \mathrm{~m}^{2}$. As calhas inferiores drenavam áreas de $0,99 \mathrm{~m}^{2}$ e $1,35 \mathrm{~m}^{2}$, respectivamente.

Um conjunto adicional de três calhas foi instalado na face exposta da trincheira, distando $1,5 \mathrm{~m}$ dos lisímetros "artificiais", sem, contudo, ter qualquer limite. Este "lisímetro" com área de drenagem livre foi 


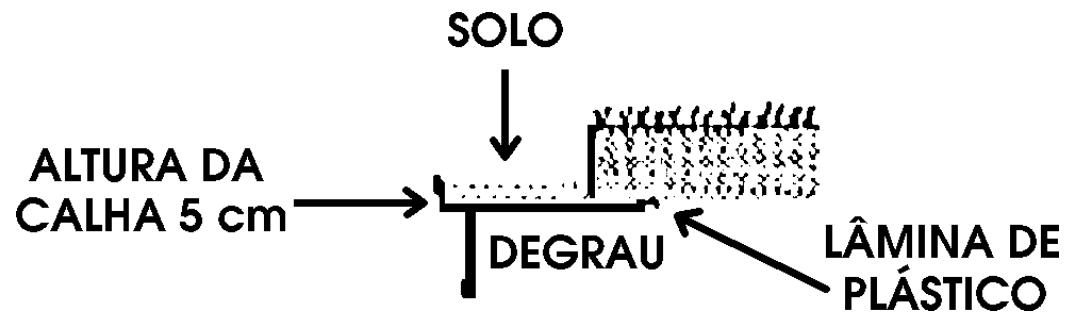

Figura 5: Detalhe de uma calha dos lisímetros preenchida com material de solo e uma lâmina de plástico para manter a continuidade hidráulica e direcionar o fluxo de água.

Figure 5: Schematc representation of the gutter and plastic sheet inserted in the soil. The gutter was partially filled with a thin layer of soil to ensure a good hydraulic contact between de guttering and the soil face.

empregado para servir como "lisímetro de controle" para indicar o total dos fluxos que poderiam ocorrer em condições naturais. O termo "controle" é usado no sentido de Cochram \& Cox (1957), i.e. um tratamento que não se tem interesse particular podendo, porém, ser utilizado para revelar por comparação, se os outros tratamentos são efetivos ou não. Neste projeto, o termo tratamento refere-se aos lisímetros separados do solo com uma camada de cimento cujos efeitos serão medidos e comparados. A necessidade de um controle deu-se por considerar que a metodologia empregada para a medição dos fluxos d'água em uma vertente é de uma maneira geral adequada. Entretanto, ocasionalmente, as condições do teste são tais que podem invalidar a utilização do método. Por exemplo, a construção de lisímetros artificiais resulta na separação dos mesmos do solo circundante e isto pode interferir no padrão temporal e na quantidade dos fluxos. Neste caso, o de controle serviu para revelar o verdadeiro padrão temporal dos fluxos e suas quantidades e serviu para a verificação do funcionamento correto dos lisímetros artificiais.

Os resultados obtidos através do "lisímetro de controle" mostraram, quando comparados com os lisímetros artificiais, um padrão muito semelhante. Portanto, de maneira geral, os resultados revelaram que os lisímetros artificiais funcionaram corretamente. Entretanto, dificuldades encontradas na delimitação da área do "lisímetro de controle", tornaram impraticáveis comparações diretas do escoamento medido com os outros lisímetros. Conseqüentemente os seus resultados, quando necessários foram usados apenas qualitativamente.

Sabe-se que os resultados dos lisímetros artificiais foram afetados por erros de vários tipos. Primeiro houve erros devidos à própria técnica empregada para medir os fluxos d'água. A própria construção dos lisímetros trouxe uma quebra na continuidade hidráulica do solo. Além disso, houve erros devido à variabilidade natural do solo (por exemplo permeabilidade) e ação de organismos. Medidas para prevenir a ação de organismos foram adotadas, como, por exemplo a colocação de uma tela de arame na face exposta dos lisímetros. Porém, este procedimento tornou-se impraticável devido à necessidade de constante remoção das calhas para limpeza, e a fixação da tela de arame provocava perturbações na estrutura do solo.

Como três réplicas dos lisímetros artificiais foram construídas, considerou-se que a variabilidade natural do solo seria controlada por tornar-se distribuída proporcionalmente entre os mesmos, pois todos tinham altitude, ângulo de declive, tipo de solo e cobertura vegetal semelhantes.

Concomitante com a preparação dos lisímetros, instalou-se uma rede de tubos de acesso para utilização de sonda de neutrons. Foram utilizados tubos de alumínio vedados em uma das extremidades com 44,5mm de diâmetro externo, 41,25mm de diâmetro interno e $1,6 \mathrm{~mm}$ de espessura, sendo que a instalação dos mesmos obedeceu as recomendações de Eeles (1969).

Como princípio básico, devido à variabilidade espacial da textura e estrutura do solo, recomenda-se instalar um projeto experimental com o maior número possível de tubos de acesso que possam ser monitorados em tempo hábil.

Um levantamento prévio das características do solo na área de estudo, possibilitou a colocação do experimento em um local com pequena variação da textura. Assim, considerando-se as características do local e o número de medições possíveis de serem feitas em um dia de trabalho, colocou-se uma rede de doze tubos de acesso, como uma matriz de 4x3 (Figura 3). O topo de cada tubo foi vedado com uma rolha de borracha para evitar a entrada de água. A altura média dos tubos em relação a superfície do solo não era menor que $5 \mathrm{~cm}$.

Neste ponto tendo-se escavado a trincheira, construído os lisímetros e instalado a rede de tubos de acesso, procedeu-se a colocação de um pluviômetro e um pluviógrafo, $1,5 \mathrm{~m}$ um do outro.

$\mathrm{Na}$ área experimental, a precipitação foi medida através de um pluviógrafo tipo Casella, com sifão natural, equipado com relógio para leitura semanal, e um pluviômetro padrão britânico.

Os dois aparelhos estavam sujeitos a erros 
provocados pelo efeito do vento, que produz turbulência. Para evitar tal problema, protegeu-se o pluviógrafo com uma parede construída com terra e recoberta de gramíneas com $30 \mathrm{~cm}$ de altura conforme descrito por Shaw (1983). O pluviômetro foi colocado com a borda ao nível do solo e recoberto com uma grade de PVC, com $1 \mathrm{~m}^{2}$ de área. O próximo passo na instrumentação da área foi a colocação dos tensiômetros.

O objetivo da instalação de tensiômetros foi a determinação da direção dos fluxos de água dentro do perfil. Foram então colocados pares de tensiômetros de manômetro de mercúrio na face exposta do perfil e declive acima, cerca de $2,5 \mathrm{~m}$ dos lisímetros. A colocação de pares de tensiômetros em diversas profundidades justifica-se pela necessidade de se obter uma idéia da variabilidade dos potenciais da água. Um objetivo, também importante, na instalação dos tensiômetros foi permitir a medida direta do grau de perturbação provocada no regime hídrico do solo, pela abertura de uma trincheira. Considerou-se tal medida necessária, devido as observações de Knapp \& Atkinson (1980), indicando que a abertura de uma trincheira pode inibir os fluxos d'água e distorcer o padrão dos potenciais ao longo da vertente. A avaliação de tais distúrbios pode ser feita através da comparação entre potenciais medidos na face exposta do perfil e declive acima, próximo aos lisímetros. Os tensiômetros usados neste experimento foram do tipo já descrito por Webster (1963), mostrados na Figura 6.

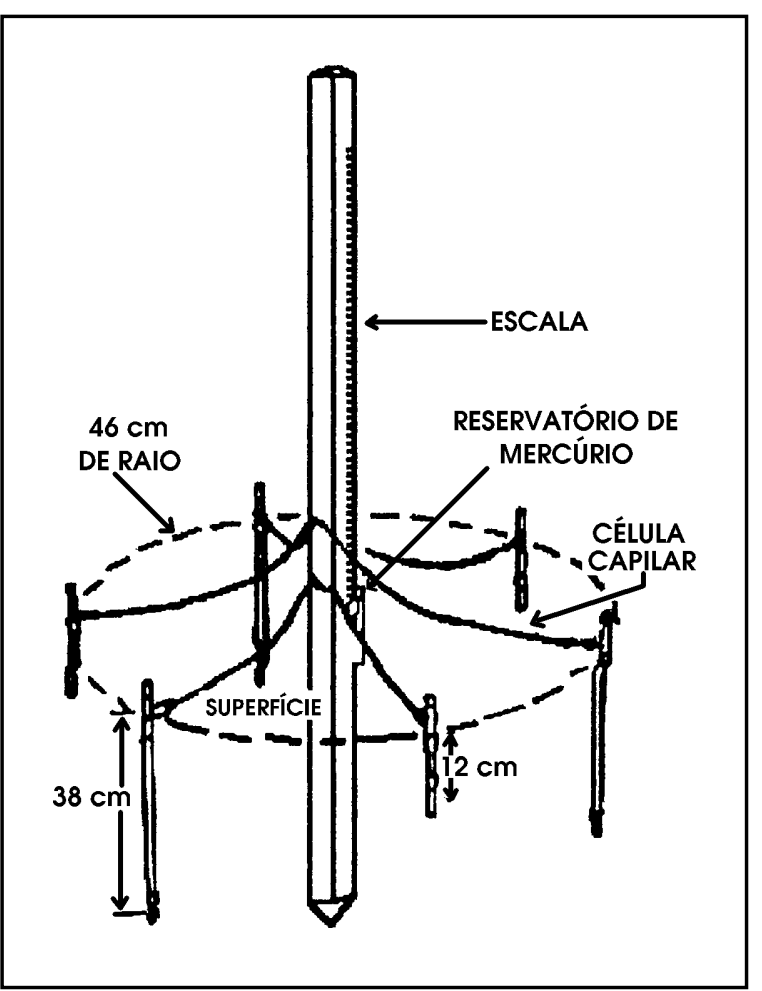

Figura 6: Diagrama simplificado de uma bateria composta por seis tensiômetros de um manômetro de mercúrio.

Figure 6: Simplified diagram of a battery composed of six tensiometers with mercury manometer.
Quatro baterias de seis tensiômetros foram instalados na face exposta da trincheira. Os pares de tensiômetros foram colocados horizontalmente com um trado, levemente inclinados no meio de cada um dos horizontes do solo nas profundidades de 10,25 e $50 \mathrm{~cm}$.

Outro conjunto de mais quatro baterias com cinco tensiômetros foi instalado verticalmente atrás de cada lisímetro com afastamento aproximado de $2,5 \mathrm{~m}$, na profundidade 10, 20, 30, 40 e $50 \mathrm{~cm}$.

É importante ressaltar que a constituição do solo pode impor limites na instalação dos tensiômetros. No caso deste experimento, o material muito pedregoso não permitiu que se obedecesse a uma mesma referência de profundidades de colocação dos tensiômetros. Isto inegavelmente trouxe um problema para a comparação entre os dois conjuntos e uma das maneiras de evitá-lo é fazer uma interpolação entre as diferentes profundidades. A construção da área de estudos completou-se com a instalação dos tensiômetros.

\section{Medições do escoamento da água}

Os volumes de água dos horizontes do solo em cada lisímetro foram coletados pelo menos uma vez por semana e, ocasionalmente, após algum evento pluviométrico significativo. Durante as medições um dos lisímetros apresentou vazamento nas calhas, o que obrigou a periódica verificação e remoção das mesmas para limpeza e recolocação no solo. Contudo, estes problemas foram sanados e os outros lisímetros não apresentaram vazamentos.

\section{Medições da precipitação pluviométrica}

A chuva também foi medida pelo menos uma vez por semana. Os problemas ocorridos foram devidos ao mau funcionamento do pluviógrafo, fato que impõe a necessidade de constante verificação do aparelho em qualquer pesquisa deste tipo. Além disso, é também altamente recomendável, trabalhar com réplicas para garantir a obtenção dos dados, no caso de falha de um dos instrumentos.

Para a análise do balanço hídrico, considerou-se que devido aos problemas de captação de chuvas por aparelhos, os dados obtidos já tinham um erro de mais ou menos 20\%, conforme sugerido por Rodda (1969).

\section{Evapotranspiração}

Não foram feitas medidas diretas de evapotranspiração na área de estudos. Usou-se dados para o local obtidos através do sistema Morecs, sigla em inglês para Sistema de Controle de Chuva e Evapotranspiração do Escritório de Meteorologia da Grã-Bretanha.

A verificação acerca da acurácia dos dados foi feita de maneira indireta usando-se os dados do potencial matricial e gradiente do potencial hidráulico do solo. O procedimento é simples e constitui-se na seleção de dias secos e chuvosos durante o período de observação. Nestes dias observou-se que a evapotranspiração real era menor que a evapotranspiração potencial, indicando "déficit" hídrico no solo. Este quadro era acompanhado 
por potenciais extremamente baixos nas camadas superiores do solo, mostrando um fluxo de água (através da observação dos fortes gradientes do potencial hidráulico) proveniente das camadas inferiores do solo para atender a demanda atmosférica. Situação inversa era observada nos dias chuvosos onde a direção do fluxo revertia-se, passando a ser da superfície para as camadas inferiores do solo, assim como também desapareceram os fortes gradientes do potencial hidráulico, indicando que o solo tinha suprimento de água adequado, fazendo com que os valores da evapotranspiração real e potencial se igualassem.

Este procedimento mostrou-se confiável, pois evidenciou que os valores da evapotranspiração real do sistemaMorecs, mesmo com erro estimado de $10 \%$, estavam seguindo a demanda da evaporação e a taxa de suprimento de água no solo.

\section{Medições do potencial de água no solo}

\section{Princípios de funcionamento dos tensiômetros}

Um tensiômetro consiste de uma cápsula porosa, geralmente de cerâmica, cheia com água de-aerada e conectada através de um tubo a um manômetro. A cápsula porosa é necessária para assegurar uma película de água contínua do solo ao tensiômetro. Ao se colocar a capsula de cerâmica, a água do seu interior entra em contacto com a solução do solo e tende a se equilibrar. Como a água do solo geralmente encontra-se sob pressão subatmosférica, ela exerce uma sucção que puxa a água do tensiômetro, que está à pressão atmosférica, diminuindo sua pressão hidrostática. Assim as variações de pressão resultantes do umedecimento e secagem do solo são indicadas pela altura do mercúrio no manômetro.

A faixa do potencial matricial que pode ser medida pelo tensiômetro é geralmente limitada a valores abaixo de uma atmosfera. Isto acontece porque a cerâmica é permeável e porosa; sucção muito alta causa entrada de ar na capsula igualando a pressão interna à atmosférica. A sucção do solo continuará a crescer, sob estas condições, entretanto não será medida pelo tensiômetro, segundo Hillel (1982).

Conforme mencionado anteriormente, o tensiômetro indica as variações do potencial matricial pela elevação e queda da coluna de mercúrio. $O$ cálculo do potencial matricial pode ser assim resumido, segundo Naysmith (1979).

$\square \mathrm{m}=\mathrm{H}-12,6 \mathrm{~L}-\mathrm{Q}(1)$

Th $=4 \mathrm{~m}-\mathrm{D}(2)$

Considerando-se a superfície do solo como referência tem-se:

$$
\begin{aligned}
& \text { Th }=\text { potencial matricial } \\
& \text { Th }=\text { potencial hidráulico } \\
& \mathrm{H}=\text { distância do topo do reservatório de mercúrio } \\
& \quad \text { à capsula porosa em cm } \\
& \mathrm{h}=\text { altura da coluna de mercúrio } \\
& \mathrm{D}=\text { profundidade }, \text { a partir da superfície do solo }
\end{aligned}
$$

$\mathrm{Q}=$ fator de correção da depressão capilar em cm $\mathrm{H}_{2} \mathrm{O}$ dada pela expressão $\mathrm{Q}=11,8 / \mathrm{D}$, onde $\mathrm{D}$ é o diâmetro interno do tubo de nylon, o qual neste caso foi de $1,5 \mathrm{~mm}$, fazendo $\mathrm{Q}=7,86$.

\section{Rotina das leituras dos tensiômetros.}

Leituras dos tensiômetros foram feitas pelo menos uma vez por semana, e ocasionalmente após as ocorrência de chuvas abundantes. Durante o verão as leituras foram interrompidas em algumas semanas quando a água do solo apresentava-se com potencial muito baixo, além da faixa de utilização dos tensiômetros. No caso específico desta pesquisa, os trabalhos foram interrompidos no inverno devido a neve e ao congelamento do solo.

A manutenção dos tensiômetros no campo é simples e no caso restringiu-se à verificação periódica para prevenir rupturas ou bloqueios nos tubos capilares e recarga dos mesmos com água de-aerada quando necessário.

Ao medir o potencial matricial encontra-se uma grande variabilidade e isto impõe a necessidade de utilizar a média de vários tensiômetros para obtenção de resultados aceitáveis. Webster (1963), sugere o uso da média geométrica como uma técnica para solucionar o problema da extrema variabilidade dos dados tensiométricos. A vantagem do uso da média geométrica está no fato de se obter uma média mais típica do que a média aritmética simples, por ser aquela menos afetada por valores extremos (Arikin \& Colton 1964).

\section{Medições da quantidade de água no solo}

Para as medições da água no solo, utilizou-se uma sonda de neutrons, levando-se em consideração a longa duração do projeto (18 meses) e a importância de obter medidas acuradas das variações do teor d'água dentro da área de estudos.

Este método para medição da água, embora tenha algumas limitações, apresenta grandes vantagens quando comparado com outros processos. A sonda de neutrons tem a vantagem de não destruir o solo, ser menos trabalhosa e mais rápida do que outras técnicas (por exemplo, o método gravimétrico). Além de permitir medições repetidas da quantidade d'água por longos períodos de tempo. Entretanto, deve-se tomar cuidado na utilização do instrumento, pelo perigo de exposição à radiação. Além do manuseio correto, é necessário, para a obtenção de resultados acurados, a elaboração de uma curva de calibração, devido às diferenças de densidade aparente e à composição química dos solos.

Dada a importância dos dados obtidos através do método acima para o projeto como um todo, é importante o entendimento dos princípios de operação e as limitações da sonda. Assim nos próximos itens, serão considerados com certo detalhe, a teoria da sonda de neutrons, a obtenção da curva de calibração, a rotina de operação da sonda e o erro das medições. 


\section{Teoria da sonda de neutrons}

A sonda de neutrons usada nesta pesquisa foi do tipo Wallingtord Soil Moisture Probe (Figura 7), conforme descrita por Bell (1976) com Amerício Berilo como fonte de neutrons. O Amerício-Berilo é usado nestas sondas por segurança e por ter meia vida de 450 anos.

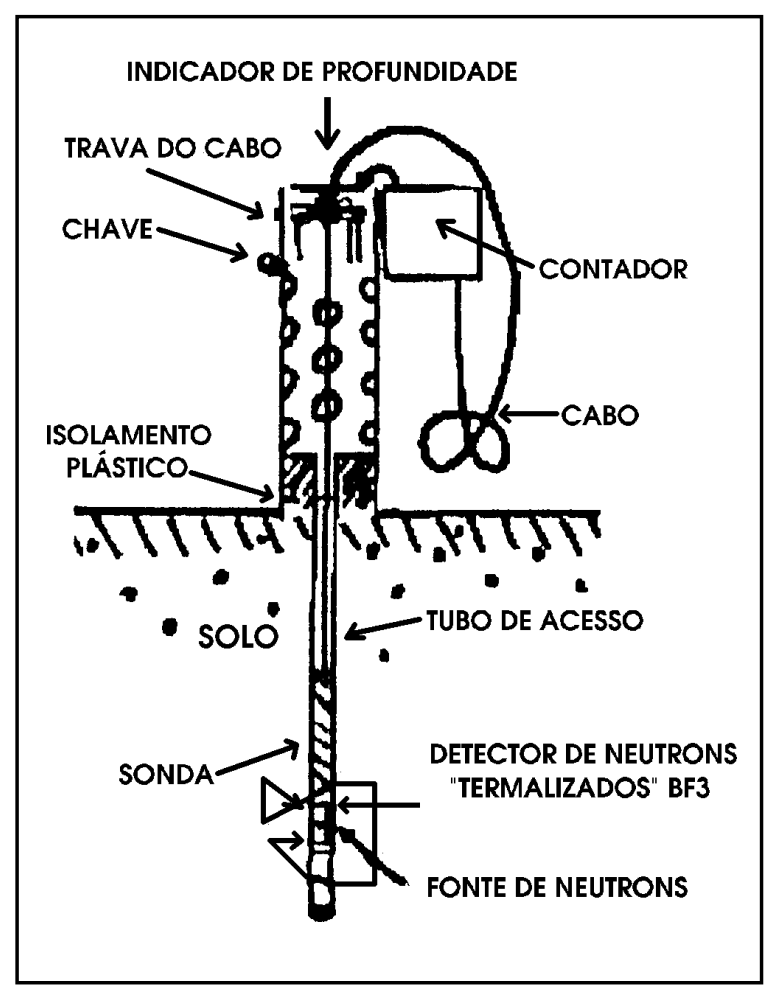

Figura 7: Esquema mostrando a sonda de neutrons em utilização no campo.

Figure 7: Schematic diagram showing the neutron probe in field work.

As medições in situ da umidade do solo que podem ser obtidas pela sonda baseiam-se na propriedade dos núcleos de hidrogênio do solo de dispersar e reduzir a velocidade dos neutrons. Na prática, a maioria dos elementos do solo têm alguma influência na dispersão e redução da velocidade dos neutrons. Entretanto, os núcleos de hidrogênio, incluindo os d'água e da matéria orgânica, exercem o principal efeito na taxa de contagem do instrumento.

Quando a sonda é introduzida no solo, os neutrons de alta energia emitidos da fonte radioativa diminuem a sua velocidade e mudam de direção por colisões elásticas com os núcleos dos átomos do solo, predominantemente aqueles do hidrogênio d'água (Gardner 1965; Bell 1956). Este processo de redução de energia cinética dos neutrons a um nível de "energia termal" dos átomos de uma substância à temperatura ambiente (termalização), permite que os neutrons sejam absorvidos por outras reações nucleares. Após as colisões, uma nuvem de neutrons "lentos", cuja densidade é grandemente uma função da quantidade d'água no solo, é gerada e então coletada por um detector de neutrons "lentos" dentro da sonda (Bell 1956). Este detector gera pulsos elétricos que são inicialmente amplificados e "formatados" antes de irem para um visor e serem mostrados como taxas de contagem média. Estas taxas de contagem podem ser traduzidas para quantidades volumétricas de água por meio da aplicação de curvas de calibração. De uma forma geral, a curva de calibração é obtida pela regressão da razão da taxa de contagem da sonda (esta razão é obtida através de duas taxas de contagem, uma no campo e outra em um tonel cheio d'água) com o volume d'água no solo obtido independentemente. O uso desta razão é eficaz, pois assegura uma continuidade dos registros e corrige distorções devido aos seguintes fatores, segundo Bell (1956), Hanks \& Aschcroft (1980):

1 - sensitividade diferente após alguma falha e posterior repouso da sonda;

2 - enfraquecimento da fonte radioativa;

3 - uso alternado de mais de uma sonda, posto que duas sondas não apresentam exatamente a mesma taxa de contagem.

\section{Métodos de calibração}

A calibração da sonda de neutrons objetiva estabelecer uma equação de calibração para a previsão do volume de água em um ponto.

Existem três métodos principais para se obter uma curva de calibração para o instrumento:

(1) calibração teórica, que é obtida através do uso de modelos teóricos desenvolvidos para a previsão do fluxo de neutrons nos solos e outros materiais de composição conhecida; (2) calibração de laboratório que envolve a compactação, em um tambor de dimensões adequadas, do solo com teores de água conhecidos e a determinação das respostas correspondentes do instrumento e (3) calibração de campo que consiste na comparação das leituras da sonda em um tubo de acesso instalado no campo, com valores do volume d'água determinado, pelo método gravimétrico, junto ao tubo de acesso. Estes métodos são descritos em Bell (1956) e Olgaard (1965). No presente trabalho, utilizou-se o método de calibração de campo, posto que não foi possível o uso da calibração teórica, uma vez que tal método requer uma análise química completa do solo, de custo muito alto, além disso, também era impraticável a sua remoção (cerca de 4 a 5 toneladas) da área de estudos, para a execução da calibração de laboratório.

Os procedimentos para a coleta de amostras in situ e o cálculo das curvas de calibração seguiram as recomendações de Greacen (1981). As curvas de calibração obtidas expressam a relação funcional entre o volume d'água contido no solo (प) e a razão da taxa de contagem da sonda de neutrons, $\mathrm{N} / \mathrm{Nw}$, de forma linear:

\footnotetext{
$\mathrm{u}=\mathrm{b} \mathrm{N} / \mathrm{Nw}+\mathrm{a}(1)$

$\mathrm{b}=$ coeficiente de calibração

$\mathrm{N}=$ taxa de contagem no campo

$\mathrm{Nw}=$ taxa de contagem na água pura

$\mathrm{a}=$ constante (intercept)
} 
Conforme mencionado anteriormente, o método da sonda de neutrons tem limitações e uma delas relacionase à dificuldade de obtenção de medidas confiáveis próximas a superfície. De acordo com Bell (1956) isto ocorre porque a densidade da nuvem de neutrons lentos é afetada pela aproximação da sonda à superfície onde ocorre uma perda de neutrons rápidos e lentos. Para a resolução deste problema utiliza-se curvas de calibração para profundidades específicas. Corrige-se também a variável $\mathrm{N}$ da equação acima para as variações de densidade aparente do solo, e os fatores de correção para superfície, de Greacen \& Schrale (1976) e Grant (1976) foram incluídos para as leituras a 5 e a $10 \mathrm{~cm} \mathrm{de}$ profundidade. As seguintes equações foram então utilizadas no presente projeto:

$$
\begin{aligned}
& \square=64.94 \mathrm{~N} / \mathrm{Nw}+8.88 \text { para } 5 \mathrm{~cm} \text { de profundidade }(2) \\
& \square=45.74 \mathrm{~N} / \mathrm{Nw}+7.585 \text { para } 10 \mathrm{~cm} \text { de profundidade }(3) \\
& \square=46.89 \mathrm{~N} / \mathrm{Nw}+4,04 \text { profundidade }>20 \mathrm{~cm}(4)
\end{aligned}
$$

\section{Rotina de medições com a sonda de neutrons}

Em princípio, as leituras no campo foram feitas semanalmente. Entretanto durante longos períodos de estiagem quando se notava que não estavam ocorrendo variações significativas da quantidade de água no solo, as leituras foram efetuadas em intervalos de quinze dias.

Antes e depois do uso da sonda, séries de cinco contagens de 64 segundos cada, eram efetuadas em um tonél cheio d'água. Estas leituras serviram para verificar se estavam ocorrendo anormalidades no instrumento e foram usadas também ao cálculo da curva de calibração uma vez que a equação baseia-se em uma razão entre contagens.

Após a colocação da sonda no tubo de acesso, a fonte radioativa descia através do perfil do solo e as leituras eram feitas a 5, 10, 20, 30, 40, 50 e $60 \mathrm{~cm}$ de profundidade. Este espaçamento justificou-se porque o raio de ação efetiva da sonda para medir as variações da quantidade de água em solo úmido é de $15 \mathrm{~cm}$ e de até $30 \mathrm{~cm}$ em terreno seco. Isto significa que o valor medido da umidade é a média para uma esfera com aqueles raios centrada no ponto de medição. Assim, 10 a $15 \mathrm{~cm}$ é o espaçamento ótimo para a leitura e não se obtém maior resolução diminuindo-se mais estes valores (Bell 1956). A duração de cada leitura era de 16 segundos, considerado um tempo de vantagem razoável para se obter uma precisão aceitável (Greacen 1981).

Os dados obtidos através da sonda de neutrons foram processados por um programa de computador desenvolvido por Naysmith (1984), elaborado para calcular a quantidade volumétrica de água no solo. Basicamente, o programa considera os dados dos tubos de acesso como 3 réplicas para cada fileira da matriz e calcula o volume médio d'água e o coeficiente de variação para cada fileira em cada profundidade. $\mathrm{O}$ programa calcula ainda a altura equivalente d'água em milímetros em cada camada e somava para todo o perfil, as variações na quantidade de água em cada camada e soma para todo o perfil as variações na quantidade d'água. Além disso, fornece a variação cumulativa da quantidade de água medida desde o início do experimento.

\section{Estimativa do erro nas medidas de variação da quantidade de água}

No presente projeto, a acurácia do total d'água medido pela sonda não foi considerada em detalhe, uma vez que o principal interesse estava na análise das variações daquela quantidade. O procedimento para se estimar o erro existente nas variações da quantidade de água entre datas consecutivas, foi descrito por Sinclair \& Willians (1979) e calculado da seguinte forma:

$$
\begin{aligned}
& S^{2}\left(\chi^{\chi} \bar{\theta}\right)=b^{2} S^{2}\left(\chi^{\chi} \bar{n}\right)+\left(\chi^{\chi} \bar{n}\right)^{2} S^{2}\left(b^{2}\right)-S^{2}\left(\chi^{\chi} \bar{n}\right) S^{2}\left(b^{2}\right) \\
& \text { Onde: } \\
& \mathbf{S}^{2}\left(\chi^{\chi} \bar{\theta}\right)=\text { erro na variação da quantidade de água } \\
& \overline{\mathrm{n}}=\text { razão média da taxa de contagem, obtida através } \\
& \mathbf{S}^{2}(\mathbf{b})=\text { variação do coeficiente de calibração } \\
& \mathbf{S}^{2}\left(\chi^{-} \overline{\mathrm{n}}\right)=\text { variação da diferença da razão média } \\
& \text { das taxas de contagem em datas } \\
& \text { consecutivas. } \\
& \mathbf{b}=\text { coeficiente da equação de calibração. }
\end{aligned}
$$

As estimativas dos erros foram obtidas considerando-se condições externas típicas, nos horizontes próximos à superfície $(5,10$ e $20 \mathrm{~cm}$ de profundidade), sujeitos a maior variabilidade.

Escolheu-se para o cálculo da componente de erro das estimativas das variações da quantidade d'água nas profundidades acima mencionadas 4 períodos, um na primavera, e os demais no início e fim do verão e final do outono. Esta escolha baseou-se no fato destes períodos marcarem as maiores variações na quantidade d'água do solo e por terem um certo grau de independência. Isto significa que as diferenças semanais do teor de água no solo não seriam independentes, uma vez que um valor alto d'água no solo em uma semana seria provavelmente alto na semana seguinte. Além disso, a escolha dos períodos acima evitou que se obtivesse uma componente de erros para condições muito semelhantes dentro de uma estação do ano ou quando o solo estivesse em capacidade de campo.

Omitindo-se os procedimentos para o cálculo da variância, chegou-se aos valores de mais ou menos $2,7 \mathrm{~mm}$ e $\pm 3,1 \mathrm{~mm}$ para o período seco (primavera, início e fim do verão) e úmido (início do outono), respectivamente. Estas estimativas de erro foram consideradas para todo o perfil e revelaram o nível de acurácia a ser atribuído ao componente de drenagem vertical, no cálculo do balanço hídrico. Em outras palavras qualquer valor de drenagem vertical menor do que o erro teve que ser descartado. 


\section{COMENTÁRIOS FINAIS}

Para complementação do projeto foi necessária a inclusão de dados de densidade aparente do solo, obtidos através de coleta de amostras, na área de estudos, em cilíndros de volume conhecido. Além disso foi elaborada uma curva de retenção de umidade, através do emprego de tanques de tensão (para cálculo da umidade disponível em capacidade de campo) e de pressão com amostras intactas (para cálculo do ponto de muchamento).

Os resultados obtidos através do experimento permitiram afirmações precisas sobre a ocorrência dos fluxos de água na vertente.

Uma síntese das informações obtidas sobre a atuação dos processos hidrológicos estudados é mostrada na Figura 8. É importante notar que a maior produção do fluxo lateral de água ocorreu no ano menos chuvoso (1984) indicando a forte influência das diferenças de potencial matricial para o surgimento de água através dos horizontes do solo. Contrariamente, o ano mais chuvoso (1985) apresentou fluxos laterais em quantidades reduzidas.
Isto demonstra que o modelo de Hewlett é o mais adequado para explicar os fluxos d'água quando há gradientes de potencial matricial. A ocorrência do escoamento superficial não foi observada, constatandose que o modelo de Horton não se aplicava às condições estudadas.

Por último, o experimento planejado mostrou-se adequado para a elucidação dos fatores de controle do fluxo de água nas vertentes. Os métodos utilizados revelaram-se eficientes, apesar das dificuldades na construção dos lisímetros e a constante necessidade de verificação dos equipamentos como um todo.

$\mathrm{Na}$ micro-escala desse trabalho pode-se verificar que a ocorrência dos fluxos de água nos horizontes do solo pode ser determinística. Contudo sabe-se que em uma escala maior, os processos que compreendem a combinação de vários micro-eventos podem ter natureza estocástica. Assim, a evolução do fenômeno estudado no tempo, em uma bacia hidrográfica, é estocástica no sentido que, embora cada micro-evento seja determinístico, em macro-escala, as condições reinantes no presente não determinam condições futuras.

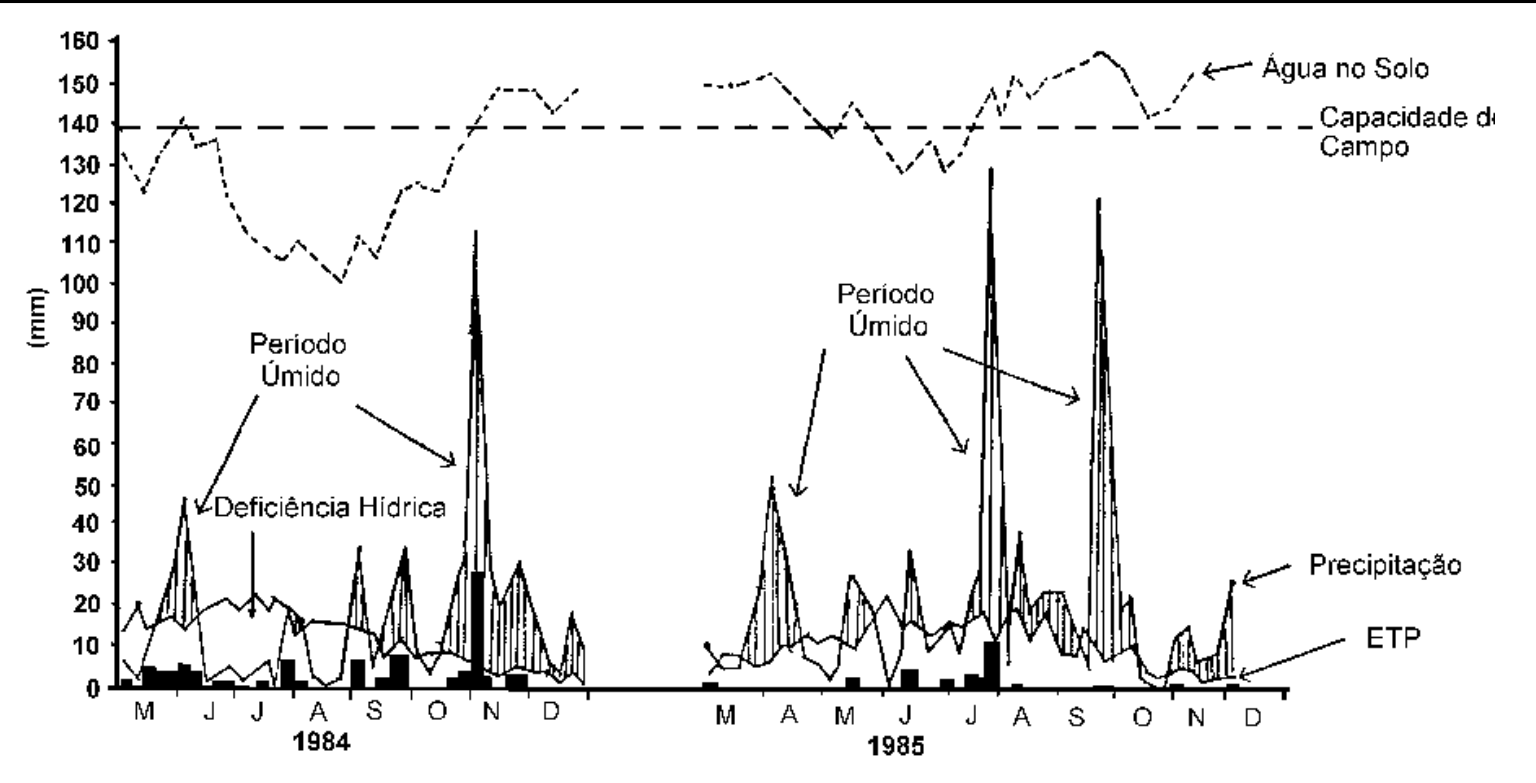

Figura 8: Variações da precipitação pluviométrica e evaporação potencial (linhas cheias); do teor de água no solo (linha pontilhada) e do escoamento medido nos lisímetros (em barras) na área de estudos.

Figure 8: Precipitation, actual evapotranspiration, total water content, and average runoff (shown as bars).

Ficou evidenciado assim, que a água escoava lateralmente, entre os horizontes do solo, durante ou após as chuvas enquanto o perfil mostrava diferenças nos valores do potencial matricial. A medida que os potenciais aumentavam e se igualavam no perfil, ou seja, o solo, ao longo da estação chuvosa, atingia capacidade de campo, a movimentação dos fluxos da água foi na componente vertical, em direção ao lençol freático, uma vez que o perfil estava completamente úmido e com boa condutividade hidráulica.
Somente probabilidades das condições futuras podem ser previstas a partir da situação presente.

Estas constatações no entanto não anulam a validade desse tipo de experimento que busca a verificação de modelos e sua adequação à realidade estudada no campo. Apenas mostram a necessidade de repetição dos experimentos para fortalecimento ou refutação total dos modelos. Somente assim será formado um corpo teórico concreto sobre os fatores que controlam os fluxos de água através do solo. 


\section{REFERÊNCIAS BIBLIOGRÁFICAS}

AMERMAN, C. R. \& McGUINESS, J. L. 1967. Plot and small watershed runoff: its relation to large areas. Transactions $A m$ Soc. Agric. Eng., 10: 464-466.

ARIKIN, H. \& COLTON, R. 1964. Statistical Methods. College Outline Series, Barnes and Noble Inc., New York.

ATKINSON, T. C. 1980. Techniques for measuring subsurface flow on hillslopes. In: Kirkby (ed.). Hillslopes Hidrology, Wiley and Sons, New York.

BALOUTSOS, G. 1985. Hillslope flow processes in a upland catchment in south east Scotland. PhD thesis, University of Edinburgh.

BELL, L. D. 1956. Soil Physics. John Wiley and Sons, New York.

BURT, T. P. \& WALLING 1984. Catchment experiments in fluvial geomorphology: a review of objectives and methodology. In : Burt and Walling (ed.). Catchment Experiments in Fluvial Geomorphology,Geo Books, England: 3-20.

COCHRAN, W. G. \& COX, G. M. 1957. Experimental designs. Wiley International, Canada.

DUBREUIL, P. L. 1985. Review of field observations of runoff generation in the tropics. Journal of Hidrology, 80: 237-264.

DUNNE, T. \& BLACK, R. D. 1970. An experimental investigation of runoff process in permeable soils. WWR , 6: 478-490.

EELES, C. W. O. 1969. Instalation of access tubes and calibration of neutron moisture probes. Institute of Hidrology, Report $n^{\circ} 7$ June 1969, Wallingford, UK.

FREEZE, R. A. 1978. Mathematical modelsof hillslope hydrology. In: Kirkby (ed.). Hillslope Hydrology, Wiley and Sons. New York.

GARDNER, W. 1965. Water content in methods of soil analysis part 1. Black, C. A., USA.

GRANT, D. R. 1975. Measurements of the soil moisture near the surface using a neutron moisture meter. Journal of Soil Science., n²6, Vol.2 : 124-129.

GREACEN, E. L. \& SCHRALE, G. 1976. The effect of bulk density on neutron meter calibration. Australian Journal of Soils Research 14 (2): 159-169.

GREACEN, E. L. 1981. Soil water assessment by neutron probe method CSIRO, Australia.
HANKS, R. J. \& ASHCROFT, G. L. 1980. Applied Soil Physics Soil Water and Temperature Application. Springer Verlag, New York.

HEWLETT, J. D. 1961. Soil moisture as a source of baseflow from steep mountain watersheds. U.S. Dept. of Agr., Southeast Forest Expt. St. Paper 132.

HEWLETT, J. D. \& HIBBERT, A. R. 1963. Moisture and energy conditions within a sloping soil mass during drainage. $J$. Geophys. Res., 68(4): 1081-1087.

HILLEL, D. 1982. Introduction to Soil Physics. Academic Press, London.

HORTON, R. E. 1933. The role of infiltration in the hydrological cycle. Trans. Amer. Geophys. Un. 14: 446-460.

KIRKBY, M. J. 1969. Infiltration, throughflow and overland flow. In: Chorley (ed.); Water, Earth and Man. Methuen, London. : 215-227.

KIRKBY, M. J. 1980. Hillslope Hidrology. Wiley and Sons. New York.

KNAPP, B. J. 1973. A system for field measurement of soil water movement. Br. Geomorphol. Res. Group, Tech. Bull. $\mathrm{n}^{\circ} 9$.

NAYSMITH, D. B. 1984. Swan 77 - A Fortran program for processing neutron probe moisture data. Edinburgh School of Agriculture.

OLGAARD, P. L. 1965. On the theory of the neutronic method for measuring the water content in the soil. Danish Atomic Energy Commission, Riso Report 97.

RODDA, J. C. 1969. The assessment of precipitation. In: Chorley (ed.). Water, Earth and Man, Methuen, London.

SHAW, E. M. 1983. Hidrology in Practice. Van Nostrand Reinhold, UK.

SHERMAN, L. K. 1932. Determination of infiltration rates from surface runoff. Trans. Amer. Geophys. Union.

SINCLAIR \& WILLIAMS 1979. Components of variance in estimating soil water content change using moisture meter. In Australian Journal of Soil Research, Vol.17: 237-247.

WEBSTER, R. 1963. A multi - cell field tensiometer unit. M. E. X. E. Report 835, Christchurch.

WEYMAN, D. R. 1973. Measurement of the downslope flow of water in a soil. Journal of Hydrology. Vol.20: 267 - 288.

WHIPKEY, R. Z. 1965. Measuring subsurface storm - a plot thecnique. U.S. Forest Service Research Note: 5 - 29. 